Research Article

\title{
An English Teaching Ability Evaluation Algorithm Based on Frequency Effect
}

\author{
Lan Xu \\ School of Foreign Languages, Guiyang University, Guiyang, Guizhou 550005, China \\ Correspondence should be addressed to Lan Xu; 160710109@stu.cuz.edu.cn
}

Received 9 October 2021; Revised 6 November 2021; Accepted 11 November 2021; Published 1 December 2021

Academic Editor: Ateeq Rehman

Copyright (c) $2021 \mathrm{Lan} \mathrm{Xu}$. This is an open access article distributed under the Creative Commons Attribution License, which permits unrestricted use, distribution, and reproduction in any medium, provided the original work is properly cited.

Background. English is one of the courses offered in all colleges and universities. The quality of English teaching is directly related to the quality of talent training and the development of students themselves. "Teaching quality evaluation" specifically refers to the education evaluation with teaching as the evaluation object. It is the core and foundation of the whole education evaluation. Teaching quality evaluation is based on certain teaching objectives and teaching norms and standards, through the systematic detection and assessment of teaching and learning. Evaluate its teaching effect and the degree of realization of teaching objectives, and use scientific and feasible methods to make corresponding value judgments to improve the process of teaching. To improve the accuracy of English teaching ability evaluation, an English teaching ability evaluation algorithm based on frequency effect is proposed. Methods. The paper proposes an English teaching ability evaluation algorithm based on frequency effect. Firstly, it constructs the evaluation index system of English teaching ability, including expert evaluation system, student evaluation system, and teacher evaluation system. Then, the indexes affecting the evaluation of English teaching ability are quantified by fuzzy synthesis, and the evaluation indexes are refined. Finally, the basic principle of frequency effect is analyzed, combined with the convolutional neural network. Results. The convolutional neural network evaluation model is constructed, the teaching ability indicators are input into the model, the final evaluation results are output, and the design of the English teaching ability evaluation algorithm based on frequency effect is completed. Conclusions. The experimental results show that this method has high accuracy and efficiency.

\section{Introduction}

Improving the quality of English teaching and promoting the long-term development of English teachers are one of the focuses of the school's work. To achieve this goal, strengthening the evaluation of English teaching quality has become a core work of the school, which is a subject worthy of serious and in-depth research [1]. Teachers' classroom teaching also affects the quality of the whole teaching. Distinguish the differences in classroom teaching and encourage cooperation among outstanding students, and at the same time, use scientific methods to operate [2]. Therefore, when evaluating a teacher's performance, in addition to completing the class hour index and the homework specified by the school, the teaching quality and effect have become a mere soft index. This has greatly dampened teachers' enthusiasm. At the same time, students' learning effect mainly comes from the classroom, and classroom teaching plays a key role in improving the whole teaching quality [3]. Due to the monopoly of "language congenital theory" in the field of language acquisition research for a long time, the role of frequency has not been paid attention to. With the expansion of the field of language acquisition research, more and more researchers are paying attention to the role of frequency in foreign language teaching. Use-based language acquisition theories such as connectionism and emergence regard frequency as an important variable [4]. The constant repetition of language experience is the foundation of people's language acquisition. The skilled use of language knowledge is based on the human brain's memory of a large number of language examples contacted in the past, not on abstract grammatical rules. Therefore, frequency is the 
decisive factor in language acquisition. However, the effect of frequency on second language acquisition is a controversial issue. Therefore, the quality supervision and evaluation mechanisms of English teaching are some of the important measures to ensure teaching quality [5]. It is imperative to establish a fair and scientific teaching quality supervision and evaluation system. Therefore, researchers in this field have done a lot of quality evaluation research and achieved some results.

The literature proposes a college teaching quality evaluation model based on a data mining algorithm, which is applied to the evaluation of English teaching quality [6]. To solve the problems existing in the process of college teaching quality evaluation and improve the accuracy of college teaching quality evaluation, a college teaching quality evaluation model based on a data mining algorithm is designed. The results show that the data mining algorithm can describe the differences between the university teaching quality grades and obtain high-precision university teaching quality evaluation results. Moreover, the error of teaching quality evaluation in colleges and universities is much smaller than the current typical teaching quality evaluation methods, which has significant advantages. However, this method has the problem of an incomplete evaluation index system, resulting in one-sided evaluation results and certain errors in evaluation accuracy. The literature proposes a dynamic evaluation model of foreign language teaching based on the Markov chain. In recent years, dynamic assessment has become a hot spot in the field of educational measurement [7]. In the quantitative measurement research of dynamic assessment, the traditional psychometric model has limitations in the assessment premise, assessment process, and predicting learners' potential, which hinders the application of dynamic assessment in foreign language teaching practice. The dynamic assessment model based on the Markov chain takes the differences of learners as the premise. This paper takes college English vocabulary teaching as an example to illustrate the application of the model in the dynamic evaluation of foreign language teaching, which provides a scientific evaluation tool for the quantitative measurement of dynamic evaluation in teaching practice. This method has faster evaluation speed and more suitable evaluation results. However, there are problems with fast data change and untimely updates of evaluation data.

The major contributions of this paper are as follows:

(i) Literature proposed an auxiliary teaching quality evaluation model based on an active learning support vector machine [8]. Considering the actual situation in many aspects, this paper constructs the evaluation index system of classroom teaching quality.

(ii) The active learning support vector machine is used to establish the classroom teaching quality evaluation model.

(iii) Experiments are carried out on the collected data set related to the teaching quality of a university, and the results are analyzed. The experimental results show that the proposed evaluation model has certain advantages in accuracy and efficiency compared with other evaluation models.

(iv) It can obtain better evaluation results of teaching quality in colleges and universities. The operation process of this method is relatively simple and the work efficiency is high, but there are few indicators for the research object, which is one-sided.

College teaching quality evaluation model based on the data mining algorithm is as follows.

The literature proposes to design a college teaching quality evaluation model based on a data mining algorithm [9].

(i) Firstly, the model studies and analyzes the relevant literature of current college teaching quality evaluation and establishes the influencing factors of college teaching quality evaluation.

(ii) Then, collect the data of influencing factors of college teaching quality and determine the grade of college teaching quality through experts.

(iii) Establish the learning sample of college teaching quality evaluation.

(iv) Finally, the BP neural network with data mining technology is introduced to train the learning samples to form the university teaching quality evaluation model, and the advantages of the university teaching quality model are analyzed through specific examples.

(v) The results show that the data mining algorithm can describe the differences between the university teaching quality grades and obtain high-precision university teaching quality evaluation results.

Because of the shortcomings of the above methods, this paper proposes an English teaching ability evaluation algorithm based on frequency effect. The technical route of this paper is as follows:

Step 1: construct the evaluation index system of English teaching ability, including expert evaluation system, student evaluation system, and teacher evaluation system.

Step 2: perform fuzzy comprehensive quantification of the indicators affecting the evaluation of English teaching ability and refinement of the evaluation indicators.

Step 3: analyze the basic principle of frequency effect, combine it with convolution neural network, construct convolution neural network evaluation model, input the teaching ability index into the model, output the final evaluation results, and complete the design of the English teaching ability evaluation algorithm based on frequency effect [10].

\section{Methods}

In section 2.1, the evaluation indicators of English teaching ability based on frequency effect are explained. In section 2.2, 
the combination of fuzzy comprehensive evaluation method and deep data mining method is used for more accurate evaluation. In section 2.3, implementation of English teaching ability evaluation algorithm based on frequency effect is discussed.

\subsection{Evaluation Algorithm of English Teaching Ability Based on Frequency Effect}

2.1.1. Construction of English Teaching Ability Evaluation Index System. Traditional English teaching ability evaluation methods evaluate English teaching ability according to the subjective cognition of experts and teachers, ignoring students' opinions, which is quite different from the real teaching results. At the same time, the pertinence of teaching ability evaluation methods is weak, and the accuracy of evaluation results is low [11]. Therefore, this paper analyzes the evaluation indicators of English teaching ability.

2.1.2. Selection of Expert Evaluation Indicators. According to the selection principle of evaluation indicators, the expert evaluation indicators are determined, which are composed of four primary indicators and nine secondary indicators [12], as shown in Table 1.

2.1.3. Selection of Student Evaluation Indicators. After analyzing the student indicators of English teaching, the indicators occupying a small proportion are screened out, and the rest are the student evaluation indicators required in this paper [13]. The determined student evaluation indicators are shown in Table 2.

2.1.4. Selection of Teacher Evaluation Indicators. Through the evaluation of teaching planning, teaching means, classroom setting, teaching attitude, and classroom performance, the teacher evaluation indicators are obtained, as shown in Table 3.

\subsection{Weight Calculation of English Teaching Ability Evaluation} Index. There are many influencing factors for English teaching ability, so it has a certain fuzzy attribute in the evaluation of English teaching ability, which is an important part of the evaluation results of English teaching ability. Therefore, this paper will introduce the combination of fuzzy comprehensive evaluation method and deep data mining method to calculate the membership of English teaching ability evaluation [14]. Through these two methods, a more accurate capability evaluation is realized. The improved fuzzy comprehensive evaluation method is used to quantify the fuzzy comprehensive evaluation of English teaching ability. The process of quantifying the evaluation results is as follows.

First of all, it is necessary to build a set of factors, evaluation set, and membership of relevant influencing factors for English teaching ability evaluation, and set $L=$ $\left\{L_{1}, L_{2}, \ldots, L_{m}\right\}$ for the set of teaching ability evaluation factors.
Set $A=\left\{a_{1}, a_{2}, \ldots, a_{n}\right\}$ to represent the teaching ability evaluation set.

Set the membership set of $B=\left\{b_{1}, b_{2}, \ldots, b_{n}\right\}$ indicating the influence factors of teaching ability; the influence weight of English teaching ability evaluation is

$$
Y=\left\{y_{1}, y_{2}, \ldots, y_{m}\right\} \text {. }
$$

Then, a subset of teaching ability quality evaluation membership was constructed after obtaining the influence weight of English teaching ability evaluation; that is,

$$
Z_{i}=\left\{z_{i 1}, z_{i 2}, \ldots, z_{i m}\right\}
$$

In the formula, $z_{i}=(i=1,2, \ldots, m)$ represents the specific membership collection of teaching ability corresponding to the $i$ index (or teaching performance of a certain subject) corresponding to English teaching ability evaluation, and the calculation formula of specific English teaching ability is

$$
z_{i j}=\frac{N_{r}}{N_{s}} .
$$

In the equation, the value range of the lower angle scale $j$ is $j=1,2, \ldots, m$.

In (3), the number of students with the specific competency rating is indicated by $N_{r}$ and $N_{s}$ for the total number of students with the English proficiency rating level involved in this assessment.

After quantifying the above English teaching ability evaluation indicators, it is necessary to calculate the weight of the above-quantified evaluation indicators by constructing an English teaching ability evaluation matrix [15]. The evaluation matrix is represented by $R$. The above English teaching ability evaluation indexes $i j$ all have a subset of evaluation membership $R_{i}$. This paper sets all English teaching ability influencing factors, constructs the evaluation matrix of $T \times V$ in the feasible domain of influence factors, sets $R R$ representation, and obtains

$$
R=\left[\begin{array}{cccc}
r_{11} & r_{12} & \ldots & r_{1 n} \\
r_{21} & r_{22} & \ldots & r_{2 n} \\
\vdots & \vdots & \ldots & \vdots \\
r_{m 1} & r_{m 2} & \ldots & r_{m n}
\end{array}\right]
$$

The evaluation membership value of influencing factors of English teaching ability is obtained through normalization. The calculation process is as follows:

$$
S^{\prime}=\left[\begin{array}{cccc}
r_{11} & r_{12} & \ldots & r_{1 n} \\
r_{21} & r_{22} & \ldots & r_{2 n} \\
\vdots & \vdots & \ldots & \vdots \\
r_{m 1} & r_{m 2} & \ldots & r_{m n}
\end{array}\right] .
$$

Parameters in (5) $S_{i}=\left(S_{i}^{\prime} / \sum_{0}^{m} S^{\prime} j(i=1,2, \ldots, n)\right)$. That is, the judgment value is

$$
S=\left(s_{1}, s_{2}, \ldots, s_{n}\right)
$$


TABLE 1: Expert evaluation indicators.

\begin{tabular}{|c|c|c|}
\hline Target & Primary index & Secondary index \\
\hline \multirow{6}{*}{$\begin{array}{l}\text { Evaluation index of English } \\
\text { teaching ability }\end{array}$} & $\begin{array}{l}\text { Teaching } \\
\text { planning }\end{array}$ & $\begin{array}{l}\text { The classroom teaching content is scientific and reasonable } \\
\text { Reasonably adjust the teaching plan to ensure the completion on time } \\
\text { The English classroom teaching content should be fully prepared }\end{array}$ \\
\hline & Teaching attitude & Strictly maintain the classroom order \\
\hline & & Help students to expand the perspective of English classroom teaching \\
\hline & & Pay attention to students' listening, hearing, reading, and writing skills, and \\
\hline & Тeac & $\begin{array}{c}\text { improve their comprehensive ability } \\
\text { Oral English clarity }\end{array}$ \\
\hline & $\begin{array}{l}\text { Classroom } \\
\text { situation }\end{array}$ & $\begin{array}{l}\text { Hearing, speaking, reading, and writing account for the whole English proportion } \\
\text { respectively } \\
\text { Oral English accounts for students answering questions }\end{array}$ \\
\hline
\end{tabular}

TABle 2: Student evaluation indicators.

\begin{tabular}{|c|c|c|}
\hline Target & Primary index & Secondary index \\
\hline \multirow{5}{*}{$\begin{array}{l}\text { Evaluation index of English teaching } \\
\text { ability }\end{array}$} & Teaching attitude & $\begin{array}{l}\text { English classroom content preparation before class } \\
\text { Properly arrange the class time and avoid being late and leaving early }\end{array}$ \\
\hline & Teaching devices & Help students expand the perspective of English classroom teaching \\
\hline & \multirow{3}{*}{$\begin{array}{l}\text { Classroom } \\
\text { situation }\end{array}$} & ing rooding and ruriting occout for the wholo Enolich \\
\hline & & $\begin{array}{l}\text { Listening, speaking, reading, and writing account for the whole English } \\
\text { probability respectively }\end{array}$ \\
\hline & & Students' activity in answering questions \\
\hline
\end{tabular}

TABle 3: Teacher evaluation indicators.

\begin{tabular}{|c|c|c|}
\hline Target & Primary index & Secondary index \\
\hline \multirow{9}{*}{$\begin{array}{l}\text { Evaluation of English teaching } \\
\text { ability }\end{array}$} & $\begin{array}{l}\text { Teaching } \\
\text { planning }\end{array}$ & $\begin{array}{l}\text { The classroom teaching content is scientific and reasonable } \\
\text { Properly adjust the teaching plan to ensure the completion of teaching tasks on time } \\
\text { English classroom teaching content is fully prepared }\end{array}$ \\
\hline & & Strictly maintain classroom order \\
\hline & Teaching attitude & Solve students' problems in time \\
\hline & & Making classroom courseware \\
\hline & & Pay attention to students' listening, speaking, reading, and writing skills and improve \\
\hline & Teaching devices & their comprehensive ability \\
\hline & & Help students expand the perspective of English classroom teaching \\
\hline & Teaching setting & $\begin{array}{l}\text { The teaching content meets the requirements of the English syllabus } \\
\text { Rich teaching content }\end{array}$ \\
\hline & $\begin{array}{l}\text { Classroom } \\
\text { situation }\end{array}$ & $\begin{array}{l}\text { Students' activity in answering questions } \\
\text { Students' oral clarity when answering questions }\end{array}$ \\
\hline
\end{tabular}

To improve the accuracy of the influence of this study on English teaching ability, the membership of English teaching ability and evaluation ability value was repeated, and the evaluation value of all influence indicators of English teaching is $S$; and the quantified fuzzy comprehensive evaluation results of English teaching ability are as follows:

$$
S \times N=\left(s_{1}, s_{2}, \ldots, s_{n}\right)\left[\begin{array}{c}
n_{1} \\
n_{2} \\
\vdots \\
n_{n}
\end{array}\right] .
$$

At the same time, according to this result, improve the effectiveness of English teaching ability evaluation.

In the fuzzy comprehensive evaluation quantification of English teaching ability, the evaluation indexes of English teaching ability are quantified by the combination of the fuzzy comprehensive evaluation method and the deep data mining method. On this basis, the evaluation matrix is constructed to determine the weight of the evaluation indexes of English teaching ability, to lay the foundation for the followup evaluation.

\subsection{Implementation of English Teaching Ability Evaluation Algorithm Based on Frequency Effect}

2.3.1. Frequency Effect Analysis. Frequency effect means that the more times something appears, the more likely it is to be recognized by people. The process of frequency acting on English teaching is a complex process, involving learners' psychological factors, cognitive factors, and the difficulty of language projects themselves [16]. Relevant scholars divide 
frequency into distribution frequency and task frequency. (i) Distribution frequency refers to the number of language items appearing in language segments or language materials, that is, the distribution law of language features. (ii) The frequency of practice refers to the individual's experience of contacting language projects, which emphasizes the role of repeated practice in English learning.

The emphasis on frequency effect can be traced back to the stimulus-response theory of behaviorism. In the period of behaviorism, frequency effect is its core concept, so the listening and speaking methods have been highly praised by many scholars. Behaviorism theory holds that, as the smallest unit, "stimulus-response" connects all learning behavior systems, and learning can strengthen this connection. The more a language unit appears and is used repeatedly, the easier it is to be strengthened and acquired. Language knowledge is a process of forming language habits along with the continuous repetition of "stimulusresponse." When learners are stimulated by the external environment, they will respond through some behavior. The external environment is a stimulus, and the behavior of learners is a response. It can be seen that "stimulation" plays an important role, and language is the response after stimulation [17]. What behaviorist learning theory emphasizes is that the length and frequency of stimulation of various language materials play a decisive role in the formation of language habits or language proficiency. The more frequently a person receives language stimuli, the stronger his language habits will be and the more proficient he will be in the language.

The input frequency can help learners strengthen the analysis of language distribution characteristics and understand the law of language input. In China, the classroom environment is one of the main ways for foreign language learners to accept language input. Learners' absorption of language mainly depends on teachers' teaching and teaching materials. To improve the quality of learners' input, the frequency effect, and its enlightenment on foreign language teaching, the correct arrangement and optimization of textbook input are an indispensable and important step in teaching reform. By reproducing and stimulating learners to pay attention to the language and carry out information processing, it can increase learners' processing depth and help learners strengthen language input, to abstract the correct frequency knowledge [18]. The frequency effect is like a network only connected. English teaching ability is regarded as each node in the network. According to the close connection of each node, the teaching quality is improved. The schematic diagram is shown in Figure 1.

S0 to S15 in Figure 1 reflect the connection frequency of English teaching ability evaluation. Each circle represents the indicators of teaching followup. Connecting these indicators step by step can finally get the final evaluation data of teaching quality. It is helpful to improve English teaching.

2.3.2. Implementation of English Teaching Ability Evaluation Algorithm. Implementation of English teaching ability evaluation algorithm according to the above basic theory of frequency effect: to realize the effective evaluation of English teaching ability, this paper combines frequency effect with convolution neural network algorithm to improve the effectiveness of English teaching ability evaluation. At this stage, the convolutional neural network has achieved certain results in teaching ability evaluation, which can effectively improve the accuracy of evaluation results. In English teaching ability evaluation, the evaluation indexes selected by experts, students, and teachers are input into a convolutional neural network for training and output as teaching ability evaluation results [19], as shown in Figure 2 .

The convolution neural network is composed of convolution layers $1-3$, pooling layers $1-3$, and full connection layers 1-3. Among them, the network initially inputs the evaluation index of English teaching ability, and the output result represents the final score of the English teaching ability evaluation. In the convolution neural network, the modified linear unit is used to obtain the construction operation function, that is,

$$
y_{j+1}=\max \left(0, t_{i} \times y_{j}+v_{j}\right)
$$

where $y_{j+1}$ describes the evaluation index values obtained when the convolutional network layer is $j, t_{i}$ describes the weight values obtained when the convolutional layer is $j$, and $v_{j}$ describes the convolutional neural network bias parameter [20]. It indicates the maximum extreme of the operation function and selects the maximum extreme pooling:

$$
y_{j+1}=\overline{\max r} y_{j}
$$

Among these, $r$ represents any pooling range in the evaluation metrics. $y_{j+1}$ represents the maximum extreme value in this range.

Input the selected index data into the convolution neural network, and set the loss function in the network training process in the mode of the norm as

$$
s=\sqrt{f(a, b)^{2}} .
$$

In the formula, $a$ represents the input training evaluation metrics, $b$ represents the network weights, and $f(a, b)$ evaluation score values are obtained on behalf of the input metric convolutional network.

After minimization, all convolution nerves are trained. In this process, the gradient descent backpropagation training method is used to obtain a new evaluation weight, namely,

$$
\nabla_{i+1}=m \times \nabla_{i}-\exists \times \frac{\partial e}{e \gamma} .
$$

Among them, $m$ represents the momentum factor in the gradient descent backpropagation, $\exists$ represents the learning probability, $i$ represents the number of network trainings, $\nabla_{i+1}$ represents the gradient increment, and $\gamma$ represents the weight attenuation value.

The training set $D$, of teaching ability feedback data, is needed to evaluate English teaching ability. Assuming that 


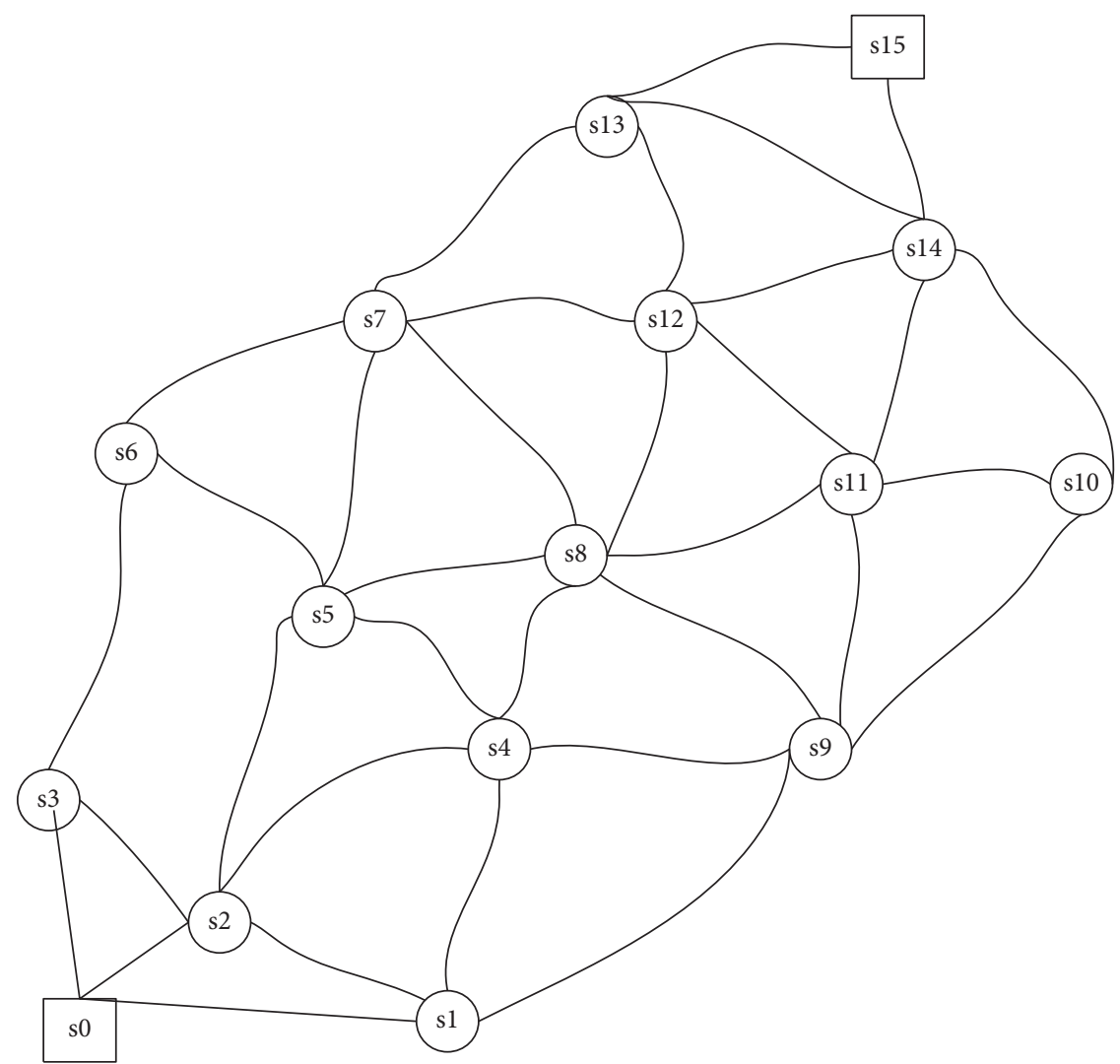

FIgURE 1: Network structure of frequency effect.

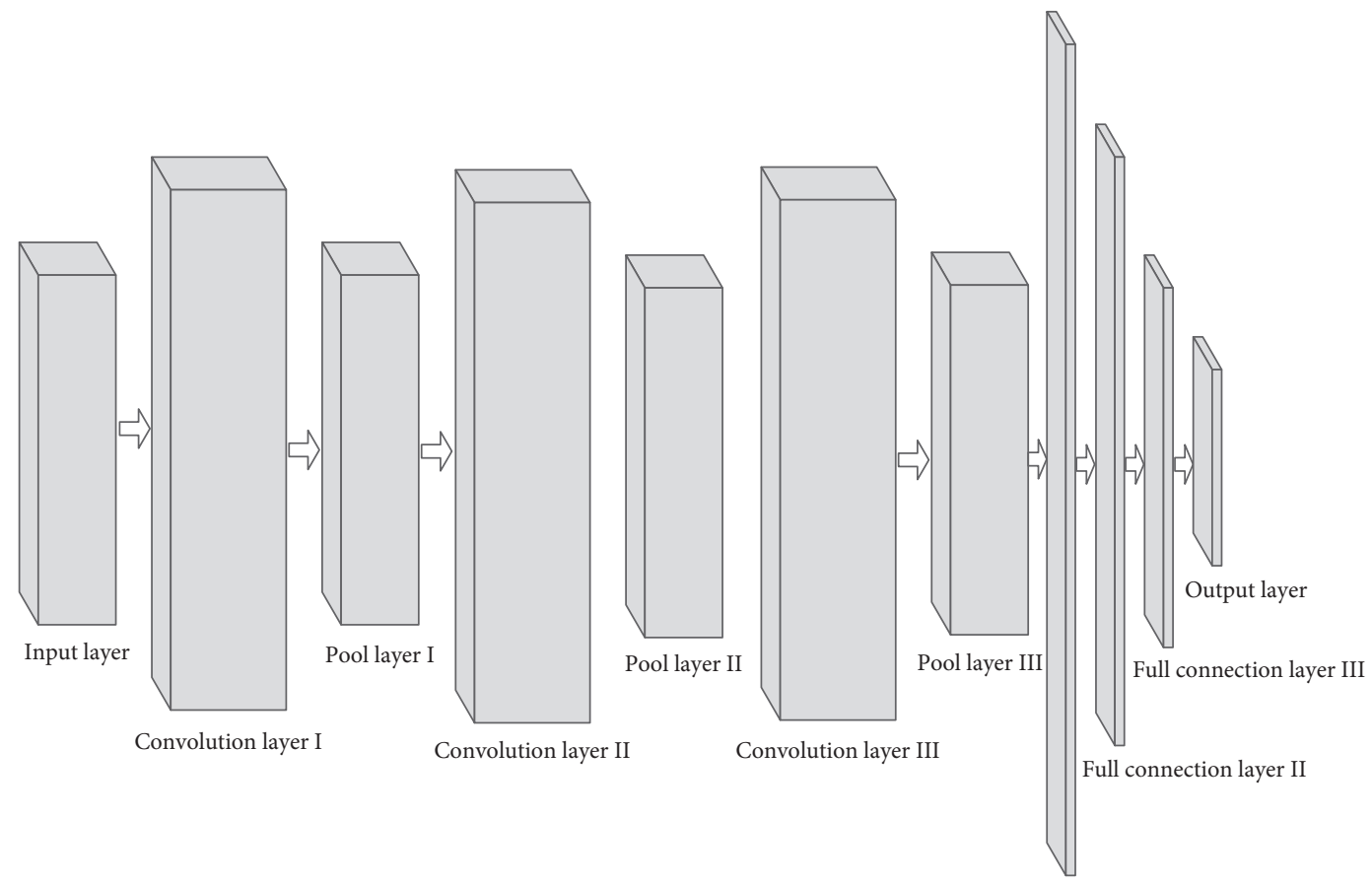

Full connection layer I

FIgURE 2: Schematic diagram of convolutional neural network construction. 
$A=\left\{A_{1}, A_{2}, \ldots, A_{n}\right\}$ represents the combination of attribute variables, the corner scale $n$ under the collection is the number of teaching subject properties, and assuming that $C=\left\{C_{1}, C_{2}, \ldots, C_{m}\right\}$ is expressed as a set of indicator subclass variables for English teaching ability assessment, the corner standard $m$ under the collection is the number of teaching resource categories, a training sample of English teaching ability is represented with $\left\{x_{1}, x_{2}, \ldots, x_{n}, C_{j}\right\}$, $j \in m$, known weights of known teaching subjects are indicated by $C_{j}$, the test sample $X$ is $\left\{x_{1}, x_{2}, \ldots, x_{n}\right\}$, and the probabilities of the test samples for calculating the English teaching ability assessment index are

$$
p\left(C_{j} \mid X\right)=\arg \max _{C_{j}} \frac{p\left(C_{j} \mid X\right) p\left(C_{j}\right)}{p(X)} .
$$

In the training process, the learning probability is set within the range of $[0.001,0.001]$. After training, the weights of the final iteration were taken as the weight value of the English teaching ability assessment index evaluated below [21].

Convolutional neural network training divides English teaching ability assessment into 27 indicators and loses them into each convolutional network and scores each index recorded as $q_{i}$, to score 27 indicators, and uses the mean of these indicators as the most final result of the whole English teaching ability assessment, that is,

$$
Q=\frac{1}{n} \sum_{i=1}^{n} q_{i}
$$

Among them, $Q$ represents the final results of the English teaching ability assessment.

The implementation process of the English teaching ability evaluation algorithm based on frequency effect is shown in Figure 3.

\section{Experimental Analysis}

In this section, the effectiveness of various methods through experiments is explained. An experimental index for different experiments is concluded which describes the accuracy of English teaching ability evaluation. To improve the accuracy of the experiment, two groups of accuracy analysis are carried out respectively.

3.1. Experimental Scheme. To verify the effectiveness of the English teaching quality evaluation algorithm, this study needs to verify the effectiveness of various methods through experiments. The experiment selects eclipse 4.7.0 as the software development platform and Java as the development language. In the experiment, the second grade of a senior experimental middle school is taken as the experimental object, and 200 college students are randomly selected as the experimental object. The relevant experimental results are obtained through multiple cross experiments. In the experiment, the sample class is taken as the object to evaluate its English classroom teaching in one week. The classroom

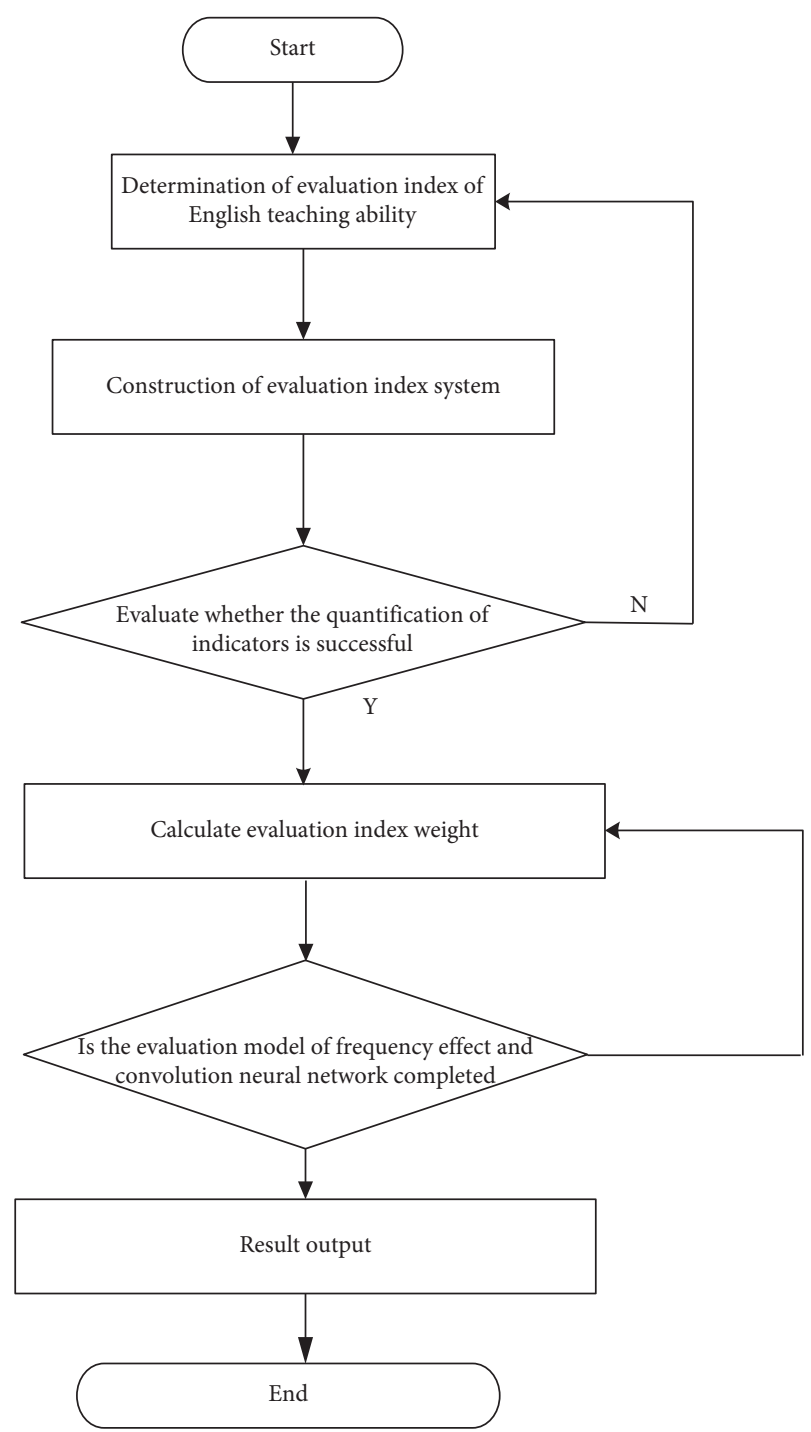

FIgURE 3: Implementation process of English teaching ability evaluation algorithm based on frequency effect.

teaching environment of English teaching is shown in Figure 4 .

3.2. Experimental Index. From the experiments, we concluded the following results:

(i) The higher the accuracy of English teaching ability evaluation, the better the teaching ability and, on the contrary, the lower the English teaching ability.

(ii) The shorter the value, the faster the evaluation speed and the better the effect.

3.3. Analysis of Experimental Results. In the experiment, by comparing this method, the college teaching quality evaluation method based on data mining algorithm and the dynamic evaluation method of foreign language teaching based on Markov chain are compared. The accuracy of English teaching ability evaluation is compared by 


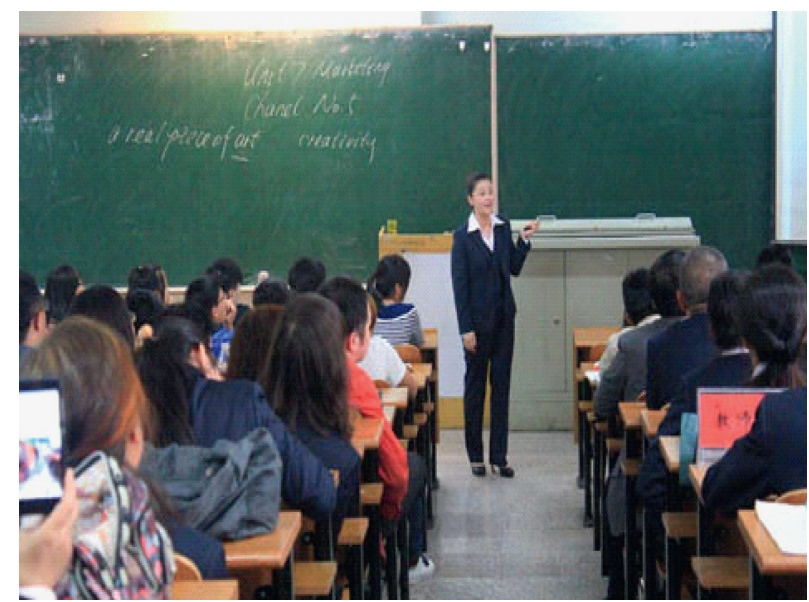

Figure 4: English classroom teaching environment.
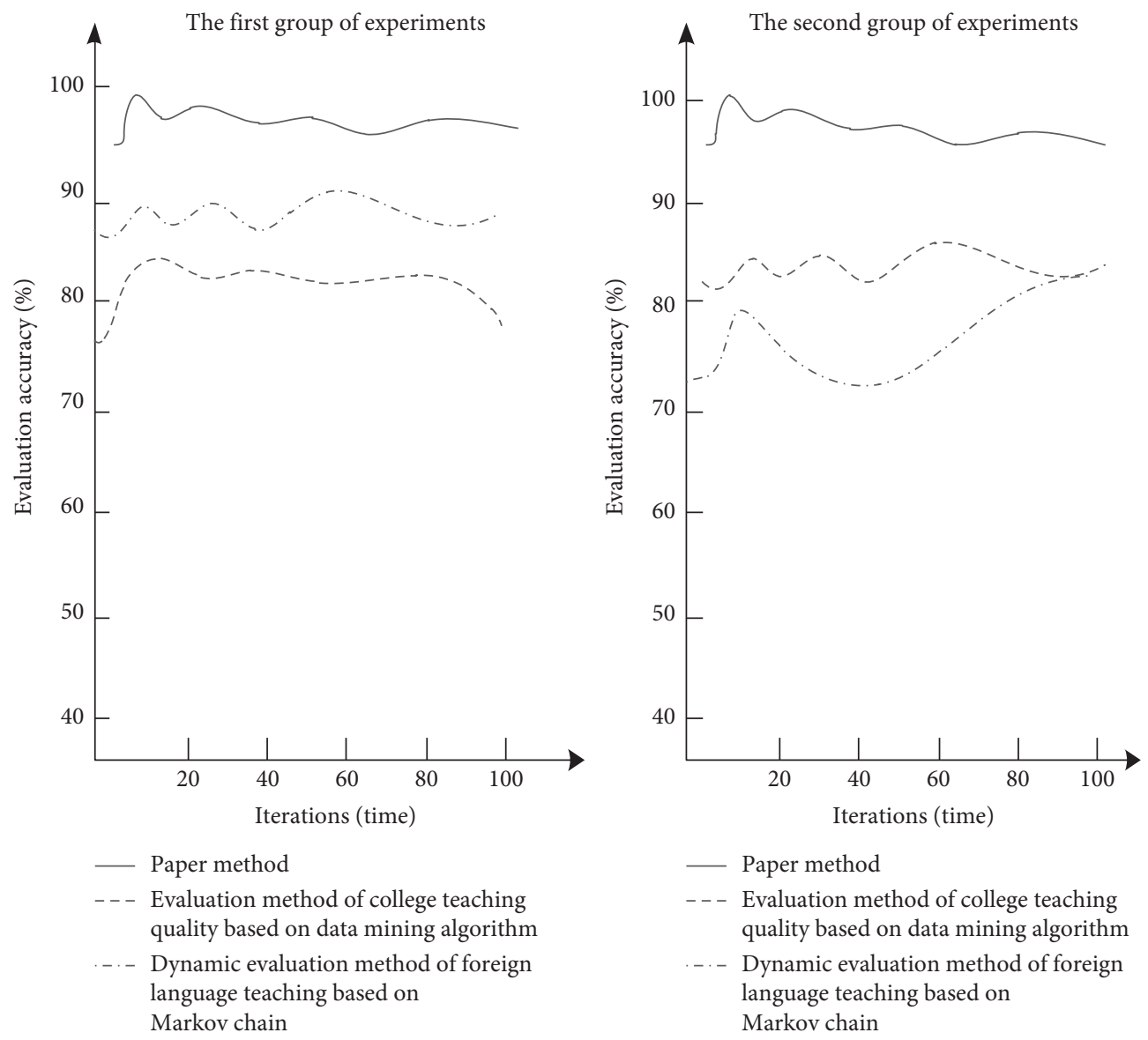

Figure 5: Accuracy analysis of English teaching ability evaluation by different methods. (a) The first group of experiments. (b) The second group of experiments.

comparing the three methods, mainly based on the students' satisfaction in the process of teachers' teaching and the results of students' classroom tests. The higher the accuracy value, the higher the evaluation effect. To improve the accuracy of the experiment, two groups of accuracy analysis are carried out respectively. The results are shown in Figure 5.
By analyzing the experimental data in Figure 5, it can be seen that there is a certain difference in the accuracy of English teaching ability evaluation by comparing the three methods by using this method, the college teaching quality evaluation method based on data mining algorithm, and the dynamic evaluation method of foreign language teaching based on Markov chain. Among them, in the first group of 
evaluation accuracy analysis, with the continuous change of evaluation times, the highest accuracy of this method can reach about $99 \%$, the highest accuracy of college teaching quality evaluation method based on data mining algorithm can reach about $91 \%$, and the highest accuracy of foreign language teaching dynamic evaluation method based on Markov chain can reach about $85 \%$. In contrast, the evaluation accuracy of this method is higher than that of the other two methods. In the second group of experiments, the highest accuracy of this method is about $99 \%$, the highest accuracy of college teaching quality evaluation method based on data mining algorithm is about $84 \%$, and the highest accuracy of foreign language teaching dynamic evaluation method based on Markov chain is about $80 \%$. From this experiment, it can be seen that the evaluation accuracy of this method is about $15 \%$ and $19 \%$ higher than the other two methods, respectively. In contrast, the evaluation accuracy of this method is higher than that of the other two methods, which verifies the effectiveness of this method.

To further verify the effectiveness of this method, the college teaching quality evaluation method based on data mining algorithm and the dynamic evaluation method of foreign language teaching based on Markov chain are experimentally analyzed to verify the time-consuming results of different methods. The results are shown in Table 4 .

By analyzing the experimental results in Table 4 , it can be seen that there are some differences in the time-consuming results of the evaluation by using this method, the university teaching quality evaluation method based on data mining algorithm, and the dynamic evaluation method of foreign language teaching based on Markov chain. When the evaluation times are 20, the evaluation time of this method is about $10.3 \mathrm{~min}$, the evaluation time of college teaching quality evaluation method based on data mining algorithm is about $13.5 \mathrm{~min}$, and the evaluation time of foreign language teaching dynamic evaluation method based on Markov chain is about $18.5 \mathrm{~min}$. When the evaluation times are 40 , the evaluation time of this method is about $9.9 \mathrm{~min}$, the evaluation time of college teaching quality evaluation method based on data mining algorithm is about $15.6 \mathrm{~min}$, and the evaluation time of foreign language teaching dynamic evaluation method based on Markov chain is about $21.0 \mathrm{~min}$. When the evaluation times are 60 , the evaluation time of this method is about $9.7 \mathrm{~min}$, the evaluation time of college teaching quality evaluation method based on data mining algorithm is about $18.4 \mathrm{~min}$, and the evaluation time of foreign language teaching dynamic evaluation method based on Markov chain is about $20.1 \mathrm{~min}$. When the evaluation times are 80 , the evaluation time of this method is about $9.5 \mathrm{~min}$, the evaluation time of college teaching quality evaluation method based on data mining algorithm is about $20.1 \mathrm{~min}$, and the evaluation time of foreign language teaching dynamic evaluation method based on Markov chain is about $23.4 \mathrm{~min}$. When the evaluation times are 100 , the evaluation time of this method is about $9.8 \mathrm{~min}$, the evaluation time of college teaching quality evaluation method based on data mining algorithm is about $22.4 \mathrm{~min}$, and the evaluation time of foreign language teaching dynamic evaluation method based on Markov chain is about
TABLE 4: Analysis of time-consuming results of evaluation by different methods (min).

\begin{tabular}{lccc}
\hline $\begin{array}{l}\text { Number of } \\
\text { assessments } \\
\text { (times) }\end{array}$ & $\begin{array}{c}\text { This } \\
\text { paper } \\
\text { method }\end{array}$ & $\begin{array}{c}\text { Evaluation } \\
\text { method of college } \\
\text { teaching quality } \\
\text { based on data } \\
\text { mining algorithm }\end{array}$ & $\begin{array}{c}\text { Dynamic } \\
\text { evaluation } \\
\text { method of foreign } \\
\text { language teaching } \\
\text { based on Markov } \\
\text { chain }\end{array}$ \\
\hline 10 & 10.2 & 12.3 & 16.3 \\
20 & 10.6 & 13.5 & 18.5 \\
30 & 10.8 & 14.5 & 20.5 \\
40 & 9.9 & 15.6 & 21.0 \\
50 & 9.8 & 16.4 & 22.3 \\
60 & 9.7 & 18.4 & 24.1 \\
70 & 9.3 & 19.3 & 24.6 \\
80 & 9.5 & 20.1 & 23.4 \\
90 & 9.6 & 20.3 & 25.1 \\
100 & 9.8 & 22.4 & 24.6 \\
\hline
\end{tabular}

$24.6 \mathrm{~min}$. In contrast, the evaluation time of this paper is the shortest, which verifies the effectiveness of this method.

\section{Conclusion}

To improve the effect of English teaching ability evaluation, this paper proposes an English teaching ability evaluation algorithm based on the frequency effect. The algorithm constructs the evaluation index system of English teaching ability, including expert evaluation system, student evaluation system, and teacher evaluation system. These indexes that affect the evaluation of English teaching ability are quantified by fuzzy synthesis, and the evaluation indexes are refined; analyze the basic principle of frequency effect, combine it with convolution neural network, construct convolution neural network evaluation model, input the teaching ability index into the model, output the final evaluation results, and complete the design of English teaching ability evaluation algorithm based on frequency effect. The experimental results show that the highest accuracy of this method is about $99 \%$, and the evaluation time is short.

\section{Data Availability}

The data used to support the findings of this study are available from the corresponding author upon request.

\section{Conflicts of Interest}

The author declares that he has no conflicts of interest.

\section{References}

[1] Z. Wang, "Interpreting common European framework of reference for languages: learning, teaching, assessment, companion volume with new descriptors," Foreign Language Testing and Teaching, vol. 12, no. 2, pp. 1145-1148, 2019.

[2] K. Haghdar, "Optimal DC source influence on selective harmonic elimination in multilevel inverters using teachinglearning based optimization," IEEE Transactions on Industrial Electronics, vol. 9, no. 99, p. 1, 2019. 
[3] B. Wu, J. Zhou, X. Ji, Y. Yin, and X. Shen, "An ameliorated teaching-learning-based optimization algorithm based study of image segmentation for multilevel thresholding using Kapur's entropy and Otsu's between class variance," Information Sciences, vol. 533, no. 15, pp. 72-107, 2020.

[4] V. Vivas-Moreno, P. Miralles-Martínez, and C. J. GómezCarrasco, "Design and assessment of a teaching program to address temporal concepts in early childhood education and primary education using stories," Palgrave Communications, vol. 8, no. 14, pp. 15-23, 2021.

[5] M. W. Zackoff, F. J. Real, D. Deblasio et al., "Objective assessment of resident teaching competency through a longitudinal, clinically integrated, resident-as-teacher curriculum," Academic Pediatrics, vol. 19, no. 6, 2019.

[6] Y. Li, "Design of university teaching quality evaluation model based on data mining algorithm," Modern Electronics Technique, vol. 43, no. 17, pp. 119-122, 2020.

[7] J. Luo, "Application of Markov chain in dynamic assessment in ESL teaching and learning," Foreign Language Teaching, vol. 11, no. 2, pp. 26-33, 2020.

[8] L. F. Wiysahnyuy and P. M. Bodang, "An assessment of history teaching strategies and promotion of professional diversity in public high schools in Mezam, Cameroon," $E d-$ ucation Quarterly Reviews, vol. 3, no. 14, pp. 56-63, 2020.

[9] M. Matore, N. Othman, and E. Matore, "The associations of peer review and self-reflections in teaching assessment with accuracy and gender from TVET teachers' feedback," in Proceedings of the Mechanical Engineering Research Day 2020, Malacca, Malaysia, December 2020.

[10] W. Ho and X. Ma, "The state-of-the-art integrations and applications of the analytic hierarchy process," European Journal of Operational Research, vol. 267, no. 2, pp. 399-414, 2018.

[11] J. Kriewaldt, R. Walker, V. Morey, and C. Morrison, "Activating and reinforcing graduates' capabilities: early lessons learned from a teaching performance assessment," Australian Educational Researcher, vol. 48, no. 4, pp. 1-16, 2021.

[12] H. Liu and Y. Zhu, "Research on the construction of teaching quality evaluation system," Journal of Physics: Conference Series, vol. 1673, no. 1, pp. 12-18, 2020.

[13] X. Wang, "Design and application of swarm intelligence algorithm in teaching quality evaluation system of normal mathematics," in Proceedings of the CIPAE 2020: 2020 International Conference on Computers, Information Processing and Advanced Education, Ottawa, Canada, October 2020.

[14] L. Zhang, S. He, W. Teng, X. Zhao, and W. Li, "Index system optimization and case demonstration of modeling design based on teaching quality evaluation for teachers," Medical Education Research and Practice, vol. 27, no. 4, pp. 554-557, 2019.

[15] M. Guo, X. Xiong, G. Feng, H. Pu, and G. Zhan, “A research on behavioral deviation and reform program of teaching quality evaluation in experiment and training of colleges," Research and Exploration in Laboratory, vol. 38, no. 5, pp. 229-232, 2019.

[16] Q. W. Dong, S. M. Wang, F. J. Han, and R. D. Zhang, "Innovative research and practice of teachers' teaching quality evaluation under the guidance of "innovation and entrepreneurship"," Procedia Computer Science, vol. 154, pp. 770-776, 2019.

[17] J. Baiges, R. Codina, I. Castañar, and E. Castillo, "A finite element reduced-order model based on adaptive mesh refinement and artificial neural networks," International Journal for Numerical Methods in Engineering, vol. 121, no. 4, pp. 588-601, 2020.

[18] T. Isabel and E. H. Benjamin, "Nomological consistency: a comprehensive test of the equivalence of different trait indexes for the same constructs," Journal of Personality, vol. 87, no. 3, pp. 715-730, 2019.

[19] Y.-X. Lu and Y.-J. Fang, "Heterogeneous network task scheduling simulation based on improved grey correlation," Computer Simulation, vol. 37, no. 10, pp. 398-402, 2020.

[20] S. Kansal, H. Kumar, S. Kaushal, and A. K. Sangaiah, "Genetic algorithm-based cost minimization pricing model for ondemand IaaS cloud service," The Journal of Supercomputing, vol. 76, no. 3, pp. 1536-1561, 2020.

[21] P. Amenta, A. Ishizaka, A. Lucadamo, G. Marcarelli, and V. Vyas, "Computing a common preference vector in a complex multi-actor and multi-group decision system in analytic hierarchy process context," Annals of Operations Research, vol. 284, no. 2, pp. 33-62, 2020. 